\title{
Desenvolvimento inicial de Erythrina velutina sob restrição hídrica
}

\author{
Mychelle Karla Teixeira de Oliveira ${ }^{1 *}$, Jeferson Luiz Dallabona Dombroski ${ }^{1}$, Rita de Cássia Araújo de Medeiros ${ }^{1}$, Ana Santana de Medeiros ${ }^{1}$ \\ ${ }^{1}$ Universidade Federal Rural do Semi-Árido, Av. Francisco Mota, 572, CEP 59.625-900, Mossoró, RN, Brasil
}

"Autor correspondente:

mymykar@gmail.com

Termos para indexação:

Espécie florestal

Estresse hídrico

Mulungu

Index terms:

Forest species

Water stress

Coral tree

Histórico do artigo:

Recebido em 11/05/2016

Aprovado em 10/09/2016

Publicado em 30/12/2016

doi: 10.4336/2016.pfb.36.88.1261
Resumo - Erythrina velutina Willd. é uma espécie arbórea, nativa do nordeste brasileiro, utilizada como ornamental e empregada em programas de reflorestamento. Neste contexto, o objetivo deste trabalho foi obter informações sobre o desenvolvimento de E. velutina sob restrição hídrica. O experimento foi conduzido em delineamento inteiramente casualizado, em parcelas subdivididas no tempo, com quatro repetições. Foram utilizados dois manejos de irrigação (sem e com estresse hídrico). Aos 56 dias após o transplantio, as mudas foram submetidas por 14 dias completos de restrição hídrica. Ao longo do experimento foram realizadas cinco coletas de mudas a serem avaliadas aos $28,42,56,70$ e 84 dias após o transplantio. As mudas foram analisadas quanto ao comprimento da parte aérea, número de folhas, diâmetro do coleto, área foliar e massa seca do caule, das folhas, das raízes, da parte aérea, da massa seca total e da relação entre a massa seca da parte aérea e das raízes. As mudas de E. velutina possuem potencial de desenvolvimento de características xeromórficas para o uso conservador de água por meio de diferentes adaptações morfológicas, como desfolha e maior desenvolvimento de raízes. As mudas de E. velutina devem ser produzidas sem restrição hídrica.

\section{Initial growth of Erythrina velutina under water restriction}

\begin{abstract}
Erythrina velutina Willd. is a wood species native to northeastern Brazil, used as ornamental and in reforestation programs. In this context, the aim of this study was to obtain information on the development of $E$. velutina under water restriction. The experiment was conducted in a completely randomized design with a split plot with four replications. It was used two irrigation management schemes (with and without water stress) where in the first treatment the plants were cultivated with daily irrigation, in the morning and afternoon. For the second treatment, at 56 days after transplanting, the seedlings went through a period of 14 days without irrigation. Throughout the experiment, there were five evaluation of growth, at 28, 42, 56, 70 and 84 days after transplanting. The seedlings were analyzed for length of aerial part, number of leaves, stem diameter, leaf area and dry mass of stem, leaves, roots, aerial part, total dry matter and the ratio of aerial part and roots dry matter. E. velutina seedlings present potential to develop xeromorphic characteristics for conservative water use through different morphological adaptations as falling leaves and increased root development. Seedlings of $E$. velutina shall be grown without water restriction.
\end{abstract}




\section{Introdução}

Frente à carência de informações sobre o crescimento e manejo de espécies florestais e os problemas ambientais que atingem os ecossistemas, reduzindo as áreas florestais, tornam-se importantes os trabalhos que subsidiem as ações de recuperação de áreas degradadas e recomposição da paisagem (Teixeira et al., 2013).

Erythrina velutina é uma espécie arbórea nativa, podendo ser encontrada em várias regiões do país, desde o Estado do Ceará até São Paulo, sendo comum em várzeas úmidas e margens de rios. Recebe diversos nomes vulgares, de acordo com cada região, como bucaré, mulungu, mulungu-da-flor-vermelha e mulungu-da-flor-amarela (Ceará); muchôco e mulungá (Minas Gerais); e mulungu (Paraíba, Pernambuco, Rio Grande do Norte, Sergipe e São Paulo) (Carvalho, 2008). É indicada para o paisagismo, para plantios em margens de corpos d'água, sendo também utilizada na medicina popular, devido às suas propriedades sudorífica, calmante, emoliente, anestésica, relaxante e anti-inflamatória. A sua madeira é útil na confecção de jangadas, brinquedos, tamancos, palitos de fósforo, mourões, estacas e caixotaria (Lorenzi \& Matos, 2008; Matos \& Queiroz, 2009; Oliveira et al., 2012).

O mulungu se destaca como tolerante à competição, pela rusticidade, resistência à seca e capacidade de fixar nitrogênio, características pertinentes a uma espécie com potencial para ser utilizada na recuperação de áreas degradadas (Holanda et al., 2010; Santos et al., 2012).

Dentre os fatores abióticos que podem interferir no desenvolvimento vegetal, destaca-se o estresse hídrico, estudado para várias espécies, que em alguns casos pode interferir até mais que o estresse salino (Moura et al., 2011), independente do tipo de solo, seja este arenoso ou argiloso (Lopes et al., 2011).

A resposta das plantas ao déficit hídrico depende dos seus estádios fenológicos e da magnitude e intensidade do estresse (Silva et al., 2008), além da variabilidade e controle genético quanto às características de crescimento (Vellini et al., 2008). A análise de crescimento é uma ferramenta que pode ser utilizada como meio acessível e preciso para avaliar o ritmo de crescimento e mensurar a contribuição de diferentes processos fisiológicos sobre o comportamento vegetal em diferentes condições de produção (Benincasa, 2003), sendo útil no estudo das respostas a estresses ambientais.
Apesar de não disponíveis para E. velutina, alguns estudos sobre resposta ao regime hídrico com outras espécies arbóreas podem ser destacados, como os trabalhos com Schinus terebinthifolius (Silva et al., 2008), Eucalyptus spp. (Vellini et al., 2008), Caesalpinia ferrea (Lenhard et al., 2010), Azadirachta indica (Martins et al., 2010), E. grandis e E. urophylla (Lopes et al., 2011), Mimosa caesalpiniifolia (Moura et al., 2011) e Guzuma ulmifolia (Scalon et al., 2011). Assim, o objetivo deste trabalho foi obter informações sobre o desenvolvimento de mudas de E. velutina na condição de restrição hídrica.

\section{Material e métodos}

O experimento foi conduzido no Viveiro de Produção de Mudas do Departamento de Ciências Vegetais da Universidade Federal Rural do Semiárido (Ufersa) em Mossoró, RN ( $5^{\circ} 11^{\prime} \mathrm{S} 1,37^{\circ} 20^{\prime} \mathrm{W}$ e altitude de $18 \mathrm{~m}$ ) no período de janeiro a fevereiro de 2012. Segundo a classificação de Thornthwaite, o clima local é semiárido, megatérmico e com pequeno ou nenhum excesso d'água durante o ano (DdAa') e de acordo com a classificação de Köppen é BSwh', seco e muito quente, com duas estações climáticas: uma seca, que geralmente compreende o período de junho a janeiro e uma chuvosa, entre os meses de fevereiro e maio (Carmo Filho et al., 1991).

As sementes de Erythrina velutina foram coletadas de plantas localizadas no campus da Ufersa e levadas ao laboratório para a realização do beneficiamento manual, retirando-se as sementes visualmente danificadas, chochas e deformadas. Foi realizada a superação da dormência pelo método de escarificação mecânica, utilizando lixa de $n^{\circ} 80$, no lado oposto ao hilo. A semeadura foi realizada em bandejas plásticas de 50 células (680 mm x $340 \mathrm{~mm}$ ), com substrato comercial do tipo Basaplant ${ }^{\mathbb{R}}$, na profundidade de $2 \mathrm{~cm}$ a $3 \mathrm{~cm}$, colocando-se as sementes com o hilo voltado para baixo (Matheus et al., 2010).

Aos 14 dias após a semeadura, as plântulas foram transplantadas para sacos plásticos de polietileno preto, com capacidade de 2,5 L, contendo substrato composto por arisco + esterco, na proporção 1:4. Antes do transplantio, retirou-se amostra do substrato para caracterização química e física, obtendo-se as seguintes características: $\mathrm{pH}=7,60 ; \mathrm{Na}^{+}=2,29 \mathrm{cmol}_{\mathrm{c}} \mathrm{dm}^{-3}$; $\mathrm{Al}^{3+}=0,00 \mathrm{cmol}_{\mathrm{c}} \mathrm{dm}^{-3} ; \mathrm{K}^{+}=1,49 \mathrm{cmol}_{\mathrm{c}} \mathrm{dm}^{-3} ; \mathrm{Ca}^{2+}=$ 
3,30 $\mathrm{cmol}_{\mathrm{c}} \mathrm{dm}^{-3} ; \mathrm{Mg}^{2+}=2,00 \mathrm{cmol}_{\mathrm{c}} \mathrm{dm}^{-3}$; soma de bases $=9,08 \mathrm{cmol} \mathrm{dm}^{-3} ; \mathrm{P}=235,07 \mathrm{mg} \mathrm{dm}^{-3} ; \mathrm{Cu}=$ $0,40 \mathrm{mg} \mathrm{dm}^{-3} ; \mathrm{Zn}=7,40 \mathrm{mg} \mathrm{dm}^{-3} ; \mathrm{Fe}=76,00 \mathrm{mg} \mathrm{dm}^{-3}$; $\mathrm{Mn}=22,40 \mathrm{mg} \mathrm{dm}^{-3} ; \mathrm{C}=3,32 \mathrm{~g} \mathrm{~kg}^{-1}$; matéria orgânica $=5,73 \mathrm{~g} \mathrm{~kg}^{-1}$; areia $=0,56 \mathrm{~kg} \mathrm{~kg}^{-1}$; silte $=0,09 \mathrm{~kg} \mathrm{~kg}^{-1}$; argila $=0,35 \mathrm{~kg} \mathrm{~kg}^{-1} \mathrm{e}$ classe textural argilo arenosa.

$\mathrm{O}$ experimento foi conduzido em delineamento inteiramente casualizado, com parcelas subdivididas no tempo, com quatro repetições, sendo a unidade experimental representada por dez plantas. Foram implantados dois manejos de irrigação (sem e com restrição hídrica), utilizando-se microaspersores. No primeiro tratamento, as plantas foram conduzidas com irrigação diária pela manhã e a tarde. As plantas do segundo tratamento, após atingirem 56 dias após o transplantio, passaram por um período de 14 dias sem irrigação. Todas foram mantidas em ambiente telado com $50 \%$ de luminosidade.

Foram realizadas cinco avaliações do crescimento das plantas, sendo aos 28, 42, 56, 70 e 84 dias após o transplantio. Em cada coleta, as mudas foram analisadas quanto ao comprimento da parte aérea (CPA), número de folhas (NF), diâmetro do coleto (DC), área foliar (AF), massa seca do caule (MSC), massa seca das folhas (MSF), massa seca das raízes (MSR), massa seca da parte aérea (MSPA), massa seca total (MST), e a relação entre a massa seca da parte aérea e a massa seca das raízes (MSPA/MSR).

A área foliar foi determinada utilizando-se o método do disco (Fernandes, 2000). Para determinação da massa seca as mudas foram fracionadas em folhas, caules e raízes. Após, foram acondicionadas em sacos de papel e colocadas em estufa com circulação forçada de ar à temperatura de $65^{\circ} \mathrm{C}$, até atingirem massa constante.

Os dados foram submetidos à análise de intervalo de confiança ao nível de 5\% de probabilidade, com barras de erros para a série de gráficos. Além disso, foi realizada a análise de variância pelo teste $\mathrm{F}$ e as médias comparadas pelo teste Tukey a $5 \%$ de probabilidade, com o uso do programa estatístico SISVAR (Ferreira, 2011).

\section{Resultados e discussão}

Foi observada aos 84 dias, diferença entre os tratamentos para comprimento da parte aérea (CPA), número de folhas (NF), diâmetro do coleto (DC) e área foliar (AF). Para todas essas variáveis, os maiores valores foram obtidos nas mudas produzidas em condição sem estresse (SE), principalmente para número de folhas (NF) e área foliar (AF), sendo aproximadamente 39 e $68 \%$ superiores, respectivamente, às plantas sob estresse hídrico (Tabela 1).

Tabela 1. Resumo da análise de variância para comprimento da parte aérea (CPA), número de folhas (NF), diâmetro do coleto (DC) e para área foliar (AF) de Erythrina velutina conduzida sem e com estresse hídrico, Mossoró, RN.

\begin{tabular}{lcccc}
\hline & CPA (cm) & NF & DC $(\mathbf{m m})$ & $\mathbf{A F}\left(\mathbf{c m}^{2}\right)$ \\
\hline Valores de F & $9,47^{* *}$ & $64,18^{* *}$ & $25,99^{* *}$ & $126,60^{* *}$ \\
CV $(\%)$ & 12,35 & 14,84 & 6,31 & 15,97 \\
\hline Tratamentos & \multicolumn{4}{c}{ Valores médios } \\
\hline Sem estresse & $39,19 \mathrm{a}$ & $5,11 \mathrm{a}$ & $10,24 \mathrm{a}$ & $2306,50 \mathrm{a}$ \\
Com estresse & $35,19 \mathrm{~b}$ & $3,68 \mathrm{~b}$ & $9,35 \mathrm{~b}$ & $1371,60 \mathrm{~b}$ \\
\hline
\end{tabular}

Médias seguidas pela mesma letra nas colunas não diferem entre si pelo teste de Tukey $(\mathrm{p} \leq 0,05) . * *=$ significativo a $1 \%$ de probabilidade pelo teste $\mathrm{F}$ e $\mathrm{ns}=$ não significativo, $\mathrm{cv}=$ coeficiente de variação.

Foi detectada diferença ao nível de $1 \%$ de probabilidade aos 84 dias entre os tratamentos para massa seca do caule (MSC), das folhas (MSF), da parte aérea (MSPA), das raízes (MSR) e massa seca total (MST), além da relação entre a massa seca da parte aérea e das raízes (MSPA/ MSR). Para todas essas variáveis, os maiores valores foram obtidos nas mudas produzidas em condição sem estresse (SE), principalmente MSC, MSPA e MSPA/ MSR (Tabela 2).

Tabela 2. Resumo da análise de variância para a massa seca do caule (MSC), das folhas (MSF), da parte aérea (MSPA), das raízes (MSR), total (MST) e relação entre a massa seca da parte aérea e das raízes (MSPA/MSR), de Erythrina velutina conduzida sem e com estresse hídrico, Mossoró, RN.

\begin{tabular}{lclcccc}
\hline & MSC (g) & MSF (g) & MSPA (g) & MSR (g) & MST (g) & MSPA/MSR (g) \\
\hline Valores de F & $4,3^{* *}$ & $42,0^{* *}$ & $100,7^{* *}$ & $181,4^{* *}$ & $45,9^{* *}$ & $158,5^{* *}$ \\
CV $(\%)$ & 1,9 & 15,0 & 11,1 & 14,3 & 9,8 & 11,3 \\
\hline \hline Tratamentos & \multicolumn{7}{c}{ Valores médios } \\
\hline Sem estresse & $8,6 \mathrm{a}$ & $2,2 \mathrm{a}$ & $10,9 \mathrm{a}$ & $1,20 \mathrm{~b}$ & $12,1 \mathrm{a}$ & $8,0 \mathrm{a}$ \\
Com estresse & $6,2 \mathrm{~b}$ & $1,7 \mathrm{~b}$ & $7,9 \mathrm{~b}$ & $2,10 \mathrm{a}$ & $10,0 \mathrm{~b}$ & $5,3 \mathrm{~b}$ \\
\hline
\end{tabular}

Médias seguidas pela mesma letra nas colunas não diferem entre si pelo teste de Tukey $(\mathrm{p} \leq 0,05)$; ** = significativo a $1 \%$ de probabilidade pelo teste $\mathrm{F}$ e ns = não significativo, $\mathrm{cv}=$ coeficiente de variação. 
Para o comprimento da parte aérea (CPA) não houve diferença significativa entre os tratamentos nas avaliações aos $28,42,56$ e 70 dias após o transplantio, enquanto que aos 84 dias as mudas na condição sem estresse hídrico apresentaram CPA superiores em 32\%, em comparação às que foram condicionadas ao estresse hídrico (Figura 1). Esta diminuição do comprimento da parte aérea das mudas pode ser o reflexo da redução das divisões e da expansão das células, provocada pela menor disponibilidade de água (Taiz \& Zeiger, 2009).

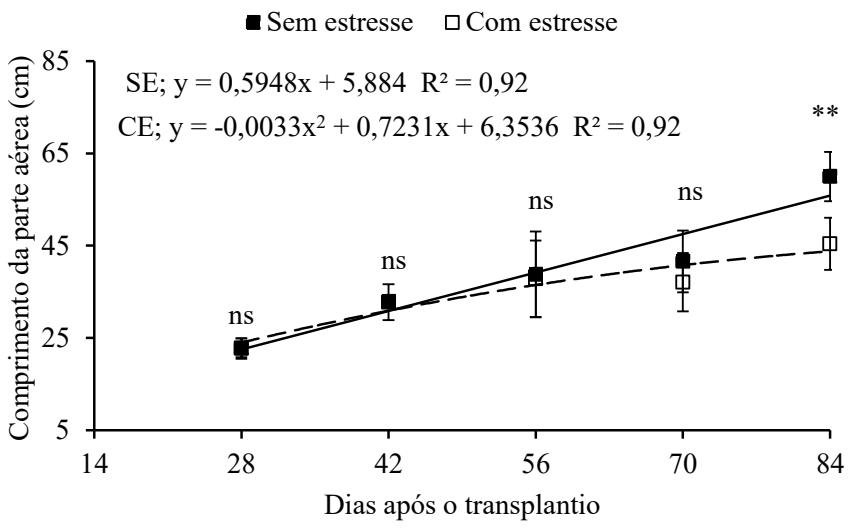

Figura 1. Comprimento da parte aérea de mudas de Erythrina velutina conduzidas sem e com estresse hídrico. As barras verticais representam os intervalos de confiança das médias ao nível de $5 \%$ de probabilidade. Os asteriscos representam diferenças significativas entre as médias em uma mesma data, pelo teste $\mathrm{F}$ ao nível de $1 \%$ (**) ou não significativo (ns).

Scalon et al. (2011) avaliaram o estresse hídrico no crescimento inicial de mudas de Guazuma ulmifolia e observaram que nos tratamentos com menor disponibilidade hídrica o CPA foi cerca de 50\% menor que nos demais tratamentos. Efeito semelhante foi observado por Martins et al. (2010), que verificaram contribuição negativa do déficit hídrico para o desenvolvimento do CPA de mudas de Azadirachta indica nos tratamentos mais severos.

Silva et al. (2010) também verificaram que nos tratamentos em que mudas de E. velutina foram cultivadas com apenas $25 \%$ da capacidade de campo, houve menor desenvolvimento em altura.

O número de folhas (NF) não diferiu significativamente nas avaliações aos 28,42 e 56 dias após transplantio, enquanto que as mudas na condição sem estresse hídrico foram superiores em $72 \%$ e $168 \%$, em comparação às na condição de estresse hídrico aos 70 e 84 dias, respectivamente. Nesta condição ocorreu a queda das folhas das mudas de E. velutina (Figura 2).

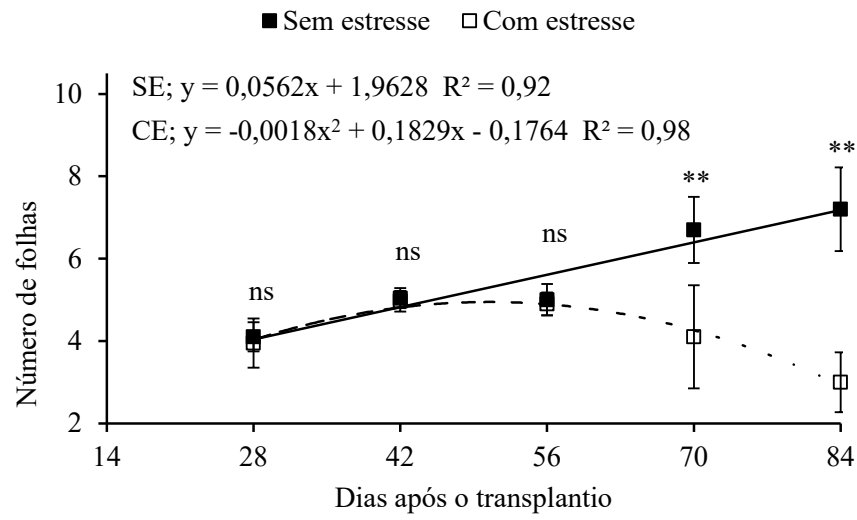

Figura 2. Número de folhas de mudas de Erythrina velutina conduzidas sem e com estresse hídrico. As barras verticais representam os intervalos de confiança das médias ao nível de $5 \%$ de probabilidade. Os asteriscos representam diferenças significativas entre as médias em uma mesma data, pelo teste $\mathrm{F}$ ao nível de $1 \%(* *)$ ou não significativo (ns).

Em plantas caducifólias a queda de folhas está relacionada ao efeito do estresse hídrico. Esse fenômeno é observado em Mimosa caesalpiniifolia, Caesalpinia pyramidalis, Auxemma oncocalyx, Caesalpinia ferrea, Calliandra spinosa, Tabebuia aurea (Dombroski et al., 2011), Artocarpus heterophyllus e Annona squamosa (Rodrigues et al., 2010). Ao comparar o crescimento de mudas de E. velutina com as relações hídricas, Silva et al. (2010) verificaram um menor número de folhas em plantas cultivadas nos tratamentos com apenas $25 \%$ da capacidade de campo. Martins et al. (2010) verificaram que houve redução no NF de Azadirachta indica, na condição de déficit hídrico.

Não foram observadas diferenças entre os tratamentos para o diâmetro do coleto (DC) nas avaliações aos 28 , 42 e 56 dias após o transplantio. As mudas na condição sem estresse hídrico foram superiores em $21 \%$ e $25 \%$, em comparação às na condição de estresse hídrico, aos 70 e 84 dias, respectivamente (Figura 3). Quando as mudas são submetidas ao estresse hídrico, podem ocorrer modificações em sua anatomia e morfologia, como a redução do diâmetro do caule, pois a falta de água reduz a pressão de turgor e, em consequência, reduz o fluxo de seiva pelos vasos condutores (Taiz \& Zeiger, 2009).

Em mudas de G. ulmifolia e C. ferrea foram observados maiores valores de DC com a maior disponibilidade de água em diferentes regimes hídricos (Lenhard et al., 2010; Scalon et al., 2011). Resultados semelhantes foram observados em mudas de $A$. indica (Martins et al., 2010) e de E. velutina (Silva et al., 2010), sendo relatados menores valores de DC quando cultivadas sob restrição hídrica. 
Foi observado que a área foliar (AF) não diferiu estatisticamente entre os tratamentos nas avaliações aos 28,42 e 56 dias após o transplantio, porém aos 70 e 84 dias as plantas na condição sem estresse hídrico apresentaram resultados superiores em $115 \%$ e $383 \%$, respectivamente, em comparação aos tratamentos na condição de estresse hídrico (Figura 4). A primeira e mais sensível resposta ao déficit hídrico de uma planta é a diminuição da turgescência, que acarreta a diminuição do processo de crescimento em extensão da planta, o que provoca uma diminuição da área foliar (Larcher, 2006).

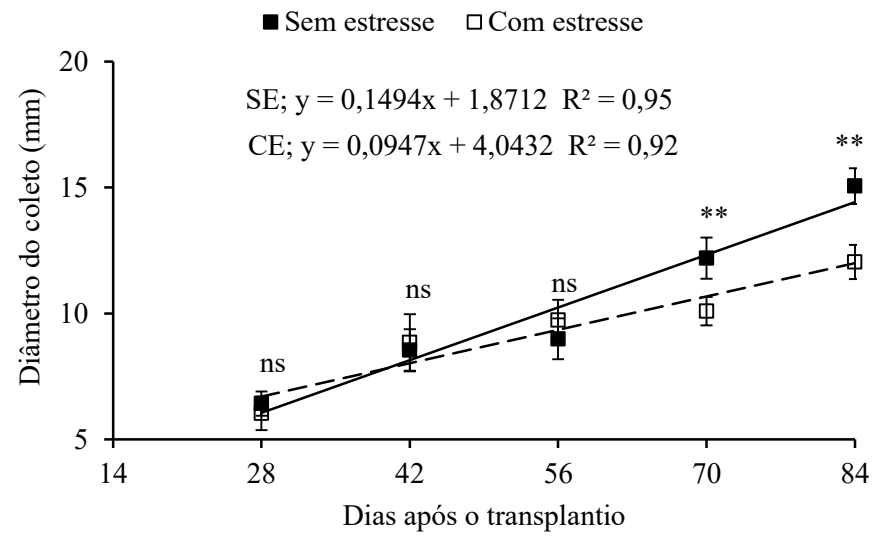

Figura 3. Diâmetro do coleto de mudas de Erythrina velutina conduzidas sem e com estresse hídrico. As barras verticais representam os intervalos de confiança das médias ao nível de $5 \%$ de probabilidade. Os asteriscos representam diferenças significativas entre as médias em uma mesma data ao nível de $1 \%(* *)$ ou não significativo (ns).

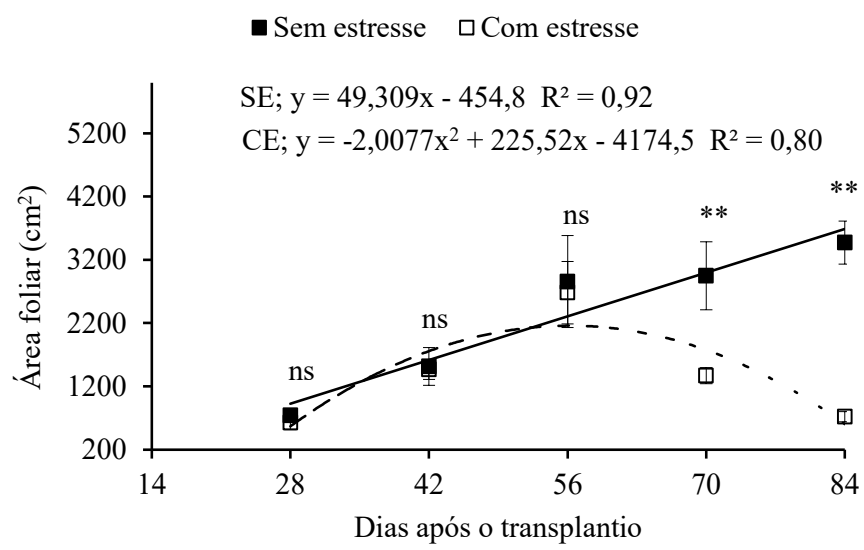

Figura 4. Área foliar de mudas de Erythrina velutina conduzidas sem e com estresse hídrico. As barras verticais representam os intervalos de confiança das médias ao nível de $5 \%$ de probabilidade. Os asteriscos representam diferenças significativas entre as médias em uma mesma data ao nível de $1 \%(* *)$ ou não significativo (ns).
As áreas foliares de mudas foram maiores quando houve maior disponibilidade hídrica do solo, em trabalhos realizados com E. velutina (Silva et al., 2010), A. indica (Martins et al., 2010) e G. ulmifolia (Scalon et al., 2011).

O estresse hídrico não apresentou efeito significativo entre os tratamentos sobre a MSC e a MSF nas avaliações aos 28, 42, 56 e 70 dias após transplantio, porém as mudas na condição sem estresse hídrico foram superiores em 91\%, em comparação às na condição de estresse hídrico, aos 84 dias (Figura 5A). Foi observada diferença significativa de MSF aos 70 e 84 dias após o transplantio das mudas na condição sem estresse hídrico, sendo superiores em 95\% e 124\% em relação às plantas conduzidas com estresse hídrico (Figura 5B).

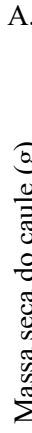

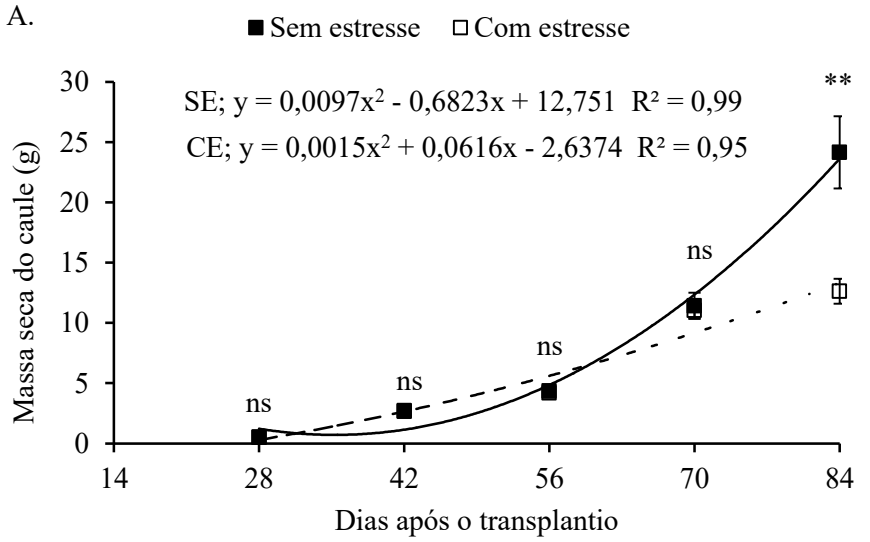

B.

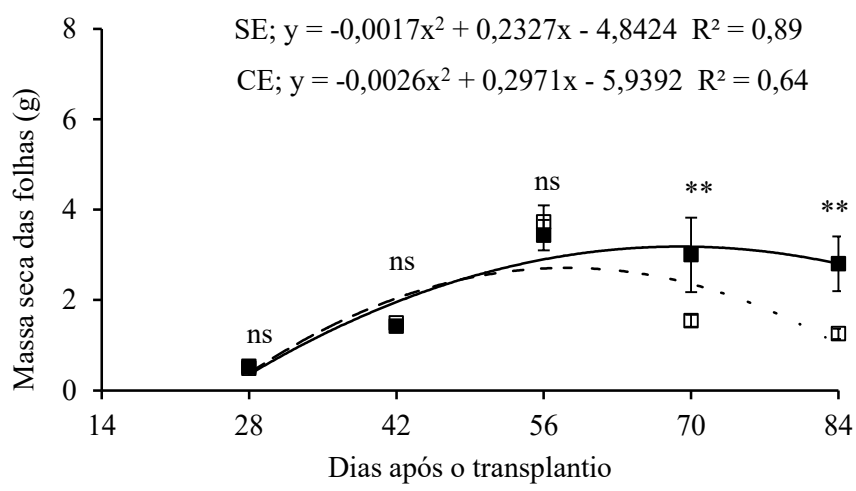

Figura 5. Massa seca do caule (A) e massa seca das folhas (B) de Erythrina velutina conduzidas sem e com estresse hídrico. As barras verticais representam os intervalos de confiança das médias ao nível de $5 \%$ de probabilidade. Os asteriscos representam diferenças significativas entre as médias em uma

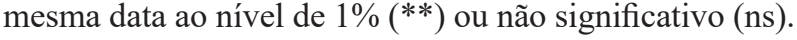


O efeito do estresse ambiental sobre o crescimento do caule em mudas tem sido menos estudado do que os demais órgãos das plantas, mas provavelmente é afetado pelas mesmas variáveis que limitam o crescimento das folhas durante o estresse hídrico (Taiz \& Zeiger, 2009). Esta diferença demonstra que as folhas são órgãos mais sensíveis que o caule sob condição de estresse hídrico, devido tanto à queda das folhas quanto à redução do limbo foliar (Dan Tatagiba et al., 2015). Diminuições da MSF em mudas produzidas em condição de estresse hídrico foram relatadas anteriormente, como por exemplo, no trabalho de Silva et al. (2008), com mudas de S. terebinthifolius, e no de Martins et al. (2010), com A. indica.

Para a MSPA não houve efeito significativo nas avaliações aos 28, 42, 56 e 70 dias após o transplantio. Aos 84 dias, as mudas sem estresse hídrico foram superiores em 94\% em relação às plantas conduzidas com restrição hídrica (Figura 6A). Para a MSR diferenças significativas foram observadas apenas nas avaliações aos 70 e 84 dias após o transplantio, sendo que na condição sem estresse hídrico os percentuais foram inferiores em $44 \%$ e $55 \%$, em relação às plantas conduzidas com estresse hídrico (Figura 6B).

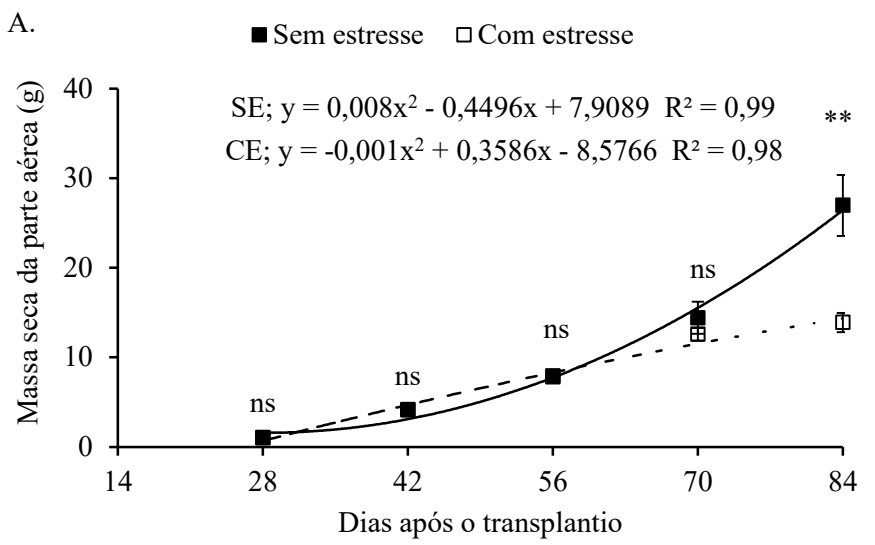

B.

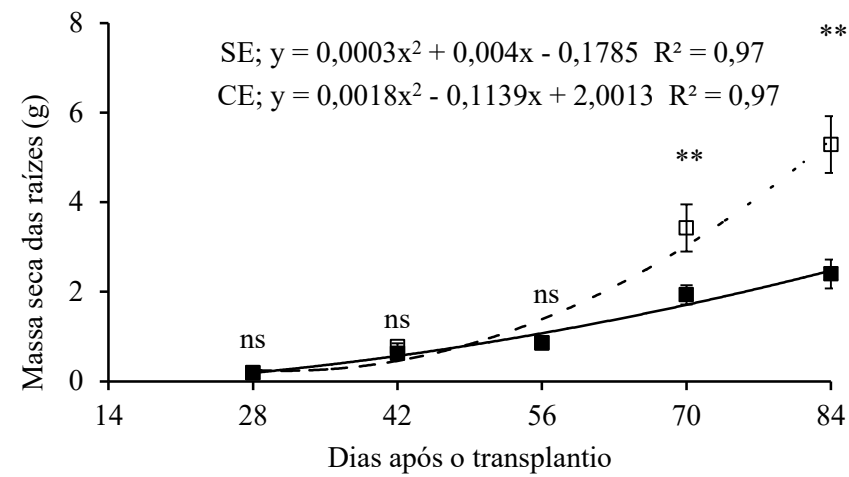

Figura 6. Massa seca da parte aérea (A) e massa seca das raízes (B) de Erytrina velutina conduzidas sem e com estresse hídrico. As barras verticais representam os intervalos de confiança das médias ao nível de $5 \%$ de probabilidade. Os asteriscos representam diferenças significativas entre as médias em uma mesma data ao nível de 1\% (**) ou não significativo (ns).

Analisando-se as Figuras 6A e 6B em conjunto, percebe-se que ao final do experimento o estresse hídrico afetou negativamente a MSPA, em contrapartida, proporcionou incremento na MSR, assemelhando-se aos resultados obtidos por Li et al. (2009) em mudas de Sophora davidii. Tal comportamento pode estar relacionado ao mecanismo de tolerância ao estresse hídrico, pois ocorre priorização do crescimento das raízes, proporcionando maior capacidade de absorver água e nutrientes. Segundo Taiz \& Zeiger (2009), o estresse hídrico eleva os níveis de $\mathrm{ABA}$, que proporciona estímulo do crescimento das raízes, redução da síntese de etileno e diminuição do crescimento do caule e aumento na abscisão foliar.

Maior MSPA em decorrência de maior disponibilidade de água também foi observado por autores que avaliaram o estresse hídrico no metabolismo e crescimento inicial de mudas de E. velutina (Silva et al., 2010) e G. ulmifolia (Scalon et al., 2011).
Scalon et al. (2011) avaliaram o estresse hídrico no crescimento inicial de mudas de G. ulmifolia, e verificaram que a MSR foi maior com a menor disponibilidade de água. O desenvolvimento inicial de mudas de E.velutina não apresentou diferença significativa quanto à massa seca das raízes, quando comparado em diferentes regimes hídricos, segundo Silva et al. (2010).

Porém, Martins et al. (2010), estudando o crescimento de plantas jovens de $A$. indica sob diferentes regimes hídricos, verificaram que o déficit hídrico diminuiu a MSR das plantas nos tratamentos mais severos. Estes autores sugerem que para o máximo crescimento na fase inicial de desenvolvimento, as plantas sejam irrigadas com $80 \%$ da capacidade de campo. Resultado semelhante foi observado por Silva et al. (2008), que ao estudarem mudas de $S$. terebinthifolius submetidas a diferentes regimes hídricos, verificaram que a MSR foi superior em regime hídrico com $75 \%$ da capacidade de campo. 
Para a relação MSPA/MSR foi observado que não houve efeito significativo aos 28,42 e 56 dias após o transplantio. Porém, aos 70 e 84 dias as mudas na condição sem estresse hídrico, foram superiores em 101 e $326 \%$ em comparação com as mudas na condição de estresse hídrico, respectivamente (Figura 7A). Plantas com estresse hídrico investem maior quantidade de fotoassimilados para o desenvolvimento radicular em detrimento da parte aérea, tendo como consequência a redução da relação entre a massa seca da parte aérea e das raízes (Taiz \& Zeiger, 2009).

A - Sem estresse $\square$ Com estresse

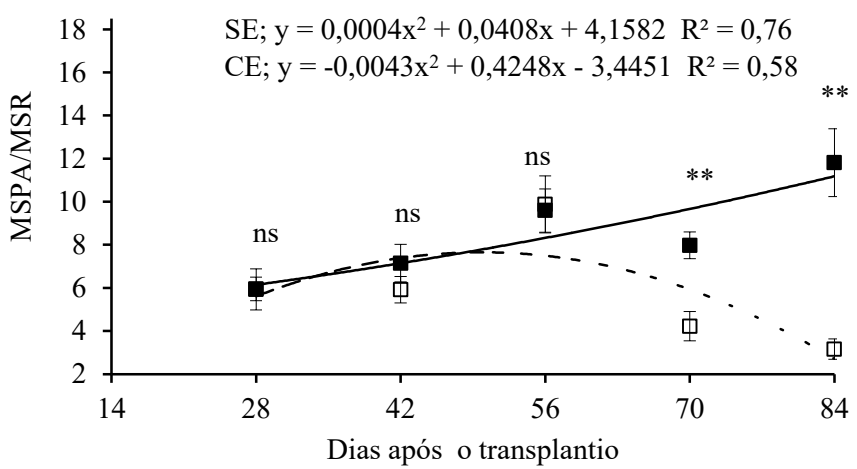

Scalon et al. (2011), avaliaram o efeito do estresse hídrico no crescimento inicial de mudas G. ulmifolia, e verificaram que a MSPA/MSR foi maior quando houve maior disponibilidade de água. No entanto, os mesmos autores constataram uma maior MSPA/MSR para o tratamento estresse severo, evidenciando uma maior alocação de recursos nas raízes.

Efeito significativo para MST foi observado apenas 84 dias após o transplantio, sendo que às mudas na condição sem estresse hídrico foram superiores em $53 \%$ em comparação as mudas na condição de estresse hídrico (Figura 7B).

B.

- Sem estresse $\square$ Com estresse

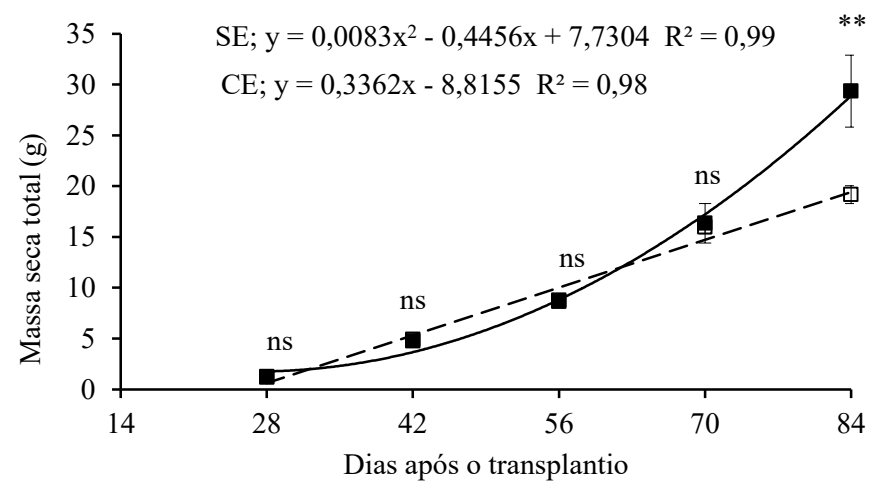

Figura 7. Relação entre a massa seca da parte aérea e das raízes (A) e massa seca total (B) de E. velutina conduzidas sem e com estresse hídrico. As barras verticais representam os intervalos de confiança das médias ao nível de 5\% de probabilidade. Os asteriscos representam diferenças significativas entre as médias em uma mesma data ao nível de $1 \%$ (**) ou não significativo (ns).

A primeira e a mais sensível resposta ao déficit hídrico é a diminuição do processo de crescimento, comprometendo os eventos subsequentes que se desenvolvem de maneira gradual (Larcher, 2006). Segundo Taiz \& Zeiger (2009) a falta de água pode provocar a redução da expansão celular, fechamento de estômatos, redução da fotossíntese, afetando severamente a produção de biomassa.

Martins et al. (2010), estudando o crescimento de plantas jovens de $A$. indica sob diferentes regimes hídricos, chegaram a concluir que o déficit hídrico diminuiu a MST das plantas nos tratamentos mais severos.

\section{Conclusões}

Mudas de mulungu (Erythrina velutina) apresentam potencial de desenvolvimento de características xeromórficas, como desfolha e maior desenvolvimento de raízes.
As mudas de E. velutina devem ser produzidas em condições sem restrição hídrica, para garantir seu melhor desenvolvimento vegetativo.

\section{Referências}

Benincasa, M. M. P. Análise de crescimento de plantas: noções básicas. Jaboticabal: FUNEP, 2003. 41 p.

Carmo Filho, F. et al. Dados climatológicos de Mossoró: um município semi-árido nordestino. Mossoró: Escola Superior de Agricultura de Mossoró, 1991. 121 p.

Carvalho, P. E. R. Mulungu (Erythrina velutina). Colombo: Embrapa Florestas, 2008. 8 p. (Embrapa Florestas. Circular técnica, 160).

Dan Tatagiba, S. et al. Determinação da máxima capacidade de retenção de água no substrato para produção de mudas de eucalipto em viveiro. Floresta, v. 45, n. 4, p. 745-754, 2015. DOI: 10.5380/ rf.v45i4.38334.

Dombroski, J. L. D. et al. Water relations of Caatinga trees in the dry season. South African Journal of Botany. v. 77, p. 430-434, 2011. DOI: 10.1016/j.sajb.2010.11.001. 
Fernandes, P. D. Análise de crescimento e desenvolvimento vegetal. Campina Grande: UFPB, Departamento de Engenharia Agrícola, 2000. 22 p.

Ferreira, D. F. Sisvar: a computer statistical analysis system. Ciência e Agrotecnologia, v. 35, n. 6, p. 1039-1042, 2011. DOI: 10.1590/ S1413-70542011000600001.

Holanda, F. S. R. et al. Crescimento inicial de espécies florestais na recomposição da mata ciliar em taludes submetidos à técnica da bioengenharia de solos. Ciência Florestal, v. 20, n. 1, p. 157-166, 2010. DOI: $10.5902 / 198050981770$.

Larcher, W. Ecofisiologia vegetal. São Carlos: Rima Artes e Textos, 2006. 532 p.

Lenhard, N. R. et al. Crescimento inicial de mudas de pau ferro (Caesalpinia ferrea Mart.ex Tul. var. Leiostachya Benth.) sob diferentes regimes hídricos. Ciência e Agrotecnologia, v. 34, n. 4, p. 870-877, 2010. DOI: 10.1590/S1413-70542010000400011.

Li, F. L. et al. Effects of water stress on growth, dry matter allocation and water-use efficiency of a leguminous species, Sophora davidii. Agroforest Systems, v. 77, n. 203, p. 193-201, 2009. DOI: 10.1007/ s10457-009-9252-8.

Lopes, J. L. W. et al. Estresse hídrico em plantio de Eucalyptus grandis vs. Eucalyptus urophylla, em função do solo, substrato e manejo hídrico de viveiro. Revista Árvore, v. 35, n. 1, p. 31-39, 2011. DOI: 10.1590/S0100-67622011000100004.

Lorenzi, H. \& Matos, F. J. A. Plantas medicinais no Brasil: nativas e exóticas. 2. ed. Nova Odessa: Instituto Plantarum, 2008. 577 p.

Martins, M. O. et al. Crescimento de plantas jovens de Nim-indiano (Azadirachta indica a. juss. - Meliaceae) sob diferentes regimes hídricos. Revista Árvore, v. 34, n. 5, p. 771-779, 2010. DOI: 10.1590/ S0100-67622010000500002.

Matheus, M. T. et al. Superação da dormência em sementes de duas espécies de Erythrina. Revista Caatinga, v. 23, n. 3, p. 48-53, 2010.

Matos, E. \& Queiroz, L. P. Árvores para cidade. Salvador: Ministério Público do Estado da Bahia: Solisluna, 2009. 340 p.
Moura, M. R. et al. Efeito do estresse hídrico e do cloreto de sódio na germinação de Mimosa caesalpiniifolia Benth. Revista Verde, v. 6 , n. 2 , p. $230-235,2011$

Oliveira, M. S. G. et al. Antinociceptive and anti-inflammatory activity of hydroalcoholic extracts and fractions from Erythrina mulungu. Revista Brasileira de Farmacognosia, v. 22, n. 1, p. $157-$ 161, 2012. DOI: 10.1590/S0102-695X2011005000210.

Rodrigues, B. M. et al. Tolerância ao déficit hídrico em plantas jovens de jaqueira e pinheira. Revista Ciência Agronômica, v. 41, n. 2, p. 245-252, 2010. DOI: 10.1590/S1806-66902010000200011.

Santos, P. L. et al. Estabelecimento de espécies florestais nativas por meio de semeadura direta para recuperação de áreas degradadas. Revista Árvore, v. 36, n. 2, p. 237-245, 2012. DOI: 10.1590/S010067622012000200005

Scalon, S. P. Q. et al. Estresse hídrico no metabolismo e crescimento inicial de mudas de mutambo (Guazuma ulmifolia Lam.). Ciência Florestal, v. 21, n. 4, p. 655-662, 2011. DOI: 10.5902/198050984510.

Silva, E. C. et al. Growth evaluation and water relations of Erythrina velutina seedlings in response to drought stress. Brazilian Journal of Plant Physiology, v. 22, n. 4, p. 225-233, 2010. DOI: 10.1590/ S1677-04202010000400002.

Silva, M. A. V. et al. Resposta estomática e produção de matéria seca em plantas jovens de aroeira submetidas a diferentes regimes hídricos. Revista Árvore, v. 32, n. 2, p. 335-344, 2008. DOI: 10.1590/ S0100-67622008000200016.

Taiz, L. \& Zeiger, E. Fisiologia vegetal. 4. ed. Porto Alegre: Artmed, 2009. 819 p.

Teixeira, W. F. et al. Atividade da enzima nitrato redutase e crescimento de Swietenia macrophylla King sob efeito de sombreamento. Floresta e Ambiente, v. 20, n. 1, p. 91-98, 2013. DOI: 10.4322 /floram.2012.068.

Vellini, A. L. T. T. et al. Respostas fisiológicas de diferentes clones de eucalipto sob diferentes regimes de irrigação. Revista Árvore, v. 32, n. 4, p. 651-663, 2008. DOI: 10.1590/S0100-67622008000400006. 